\title{
7 Passerine Station Laboratory Working Routine
}

An optimal laboratory routine is essential for the collection of high quality (and large amounts of) data without danger to the birds. This routine should be as parsimonious and as effective as possible. On one hand, it should be flexible, and on the other hand, separate operations should be strictly standardized in order to be compatible.

A few routine levels will be described:

1. Normal routine where a standard set of data is collected,

2. Extended routine where all (planned) additional data are collected,

3. Reduced data collecting routine as a part of the "alarm routine" when too many birds are caught to perform standard working procedures.

It must be stressed here that "normal" and "extended" routines may be differentiated according to the station preferences, based on its scientific scope of work and/or concentration on different groups of birds.

Depending on the number of birds waiting for treatment and the existing routine, the work performed at the laboratory may be organized according to one of two guidelines: (1) if the number of birds is low or moderate, the working team is made up of two people, and (2) when birds are numerous, the team is made up of three people. The experience of the people involved and their training in the work as a team collectively decides the meaning of "numerous".

Note that it is very inefficient to have the same person ringing and the same time entering data; this situation should be avoided as much as possible. It is very time-consuming and can lead to errors.

Generally, the laboratory routines are based on strict attendance to the rules as earlier presented, particularly those in the Netting and How to Arrange Trapping with Heligoland Traps sections. As a short reminder: the birds transported to the laboratory are hung in bags on a row of hooks at the edge of the laboratory table (Figure 3.14) and they are sorted by species (only one species per bag and bags with the same species in a row) and by ring sizes (all species ringed with the same ring type should neighbour at hooks). The sequence of ring types should be permanently fixed in order to obtain the same working procedure, e.g. the smallest type always to the left of the row and subsequent sizes following to the right. The position of the bags is decided by the present working team. The seats of people in the working procedure must be placed side by side, with the ringer seat to the left (right-handed persons assumed). The seat for a third person in the three-person working group should be located at the other side of the table so that the writer is able to hear dictation from both working persons. The most useful seat for the ringer is a soft, comfortable armchair, for you sometimes spend a few hours ringing when the birds rush. The seat should be of such height that the ringer's thighs are situated horizontally when he sits with knees close together and feet a little bit apart. This position will allow the ringer to put his ruler on his lap while not in use. Seats for the other people should be more elevated, in order 
to make writing on the field-form lying on the table comfortable enough. Sometimes, in the two person procedure, it is preferable to have the field-form resting on a hard surface situated on the lap of the writer, while he sits in exactly the same position as the ringer - this way, it is more comfortable to pass the birds to the ringer.

\subsection{Normal Routine}

\subsubsection{Two-Person Procedure}

Out of the two people working in the team, one is (as a basic rule - see below) designated as the ringer. The ringer rings and takes all measurements, while the second person acts as the writer, noting dictated data in the field-form. In order to simplify, record the ringing/measuring procedure in a strictly defined order, fixed to the sequence of columns in the field-form. Strict standardization of the working procedure is very useful when many people are taking part in laboratory work, changing their roles while bird processing, or alternating between bird stations working within the network.

In normal procedure, the ringer removes the bird from the bag (holding the bird in the standard manner) and starts with ringing. It is a good custom to start a new hour ringing with the same species which was the last input of the particular field-form, e.g. if the last bird ringed was a Robin - start with the robins, if there are any. This saves time when entering data into a computer file. If this rule causes any difficulties (we do not know in which bag the Robin is) - disregard it.

Standard dictation goes as follows:

Hour - this is dictated only when birds from more than one control are waiting. Otherwise, Date and Hour are written by the writer without dictation and it is his/her responsibility to make a correct input.

\section{Ring number and Status -}

1. For a new bird, not yet ringed, the ringer dictates ring type and the two last digits of the ring number; if the ring is the first one on the ringing-sheet, the writer calls for a full ring number and the ringer provides it; after that, the writer must check whether the number given is a subsequent ring number. If not, the writer must stop the procedure and the problem must be solved (lack of a ring? wrong sequence of rings? false ring type? new series? retrap or control?). The writer is responsible for noting the correct ring number. The first part of the ring number (ring number without last two digits) is written into the column "Series...", the last two digits into column "no.". Subsequent numbers in row are noted as only two last digits in the column "no."

Note: the ringed individual is then measured according to the established standard (see below). 
2. A re-trapped bird is reported by the ringer first as "retrap", followed by the full ring number with heading letters (ring type). The writer notes the type of ring in the column "Type" and full number into the column "Series....". Then, he writes " $R$ " in column "Status".

Note: re-traps are usually not measured, but fat score and weight are noted. However, measuring re-traps could be useful for studies on measurement calibration of ringers working at the station and ascertaining the reproducibility of measurements.

3. Control: a bird ringed elsewhere with a ring issued by the same ringing centre or ringed at the station in previous seasons. The ringer reports it first as "control" and dictates full number; then he asks the writer to read the recorded ring number and compares the recorded number with the ring. For controls, as for re-traps, full ring number is written in the column "Series...". The status of such control is noted as " $C$ ".

Note: Controls are measured according to the newly ringed birds standard.

4. Foreign control: the ring number is noted as usual but re-dictation is obligatory; the ring number last column should be filled with sign “-”. Status is noted as " $V$ ". In "Comments" it must be written as the full inscription on the ring (double reading should be applied).

Note: Foreign controls are measured according to the newly ringed birds standard.

Species name: is coded as explained earlier. The ringer must dictate the code - not the bird name, unless the writer is a qualified ringer. If same as the previous individual, the bird name may be left out and the writer fills the name position with a vertical stroke. Note, however, that this is a slightly dangerous custom. The writer should be cautious and he should check with the ringer. Generally, it is allowed only when the writer is well trained.

Sex and Age: dictate codes unless the writer is trained; sex should be dictated with words when scientific symbols are used in noting. Note: sex and age notations can be fixed after fat scoring (the ringer is able to see some sexing/ageing characteristics, e.g. sex of the Great Tit, when studying fat deposits). It is possible just before Wingformula too - in many cases, opening the wing is needed both for age discrimination (e.g. contrast within greater coverts), and for starting wing-formula measurement.

\section{Fat scoring \\ Wing-formula \\ Wing-length \\ Tail-length}

Weight: these are dictated according to rules specified in standard descriptions of methods. Such a sequence is used because a sequence of measurements, done with the same ruler, will save time. It was carefully optimised from the ergonomic point of view, so the bird and the ruler moves are limited. This is very important when the bird count gets high!

Ringer: ringer's code is written at the beginning of every sheet (without being dictated). 
This basic two-person procedure can be modified according to number of birds and experience of the writer:

(a) The writer can remove the bird from the bag or box and pass it to the ringer, or, if very well trained - ring it and pass it to the ringer, who becomes the measurer. This option requires remembering of some data and sometimes can lead to errors;

(b) The writer can be the person who reads the result from weighing.

Applying a three-person and non-standard version (a) of the two-person procedure requires quick and safe passing of the bird from hand to hand. Passing of the bird when both people hold it by the standard holding method is quick, and birds seldom escape (Figure 7.1): the bird holder takes the bird's bill with the left hand and gently pulls it. The bird's neck becomes longer, and simultaneously, the right hand turns the bird's body slightly and holds it with the tips of four fingers; the bird receiver creates a fissure between his index and middle fingers of his right hand and directs it to the bird holder. The bird's neck is placed between two fingers of the receiver. The receiver need not look at the passed bird and he closes fingers when he feels the bird's neck between them. The passing procedure should be trained in advance before there is need for it during a rush of birds.

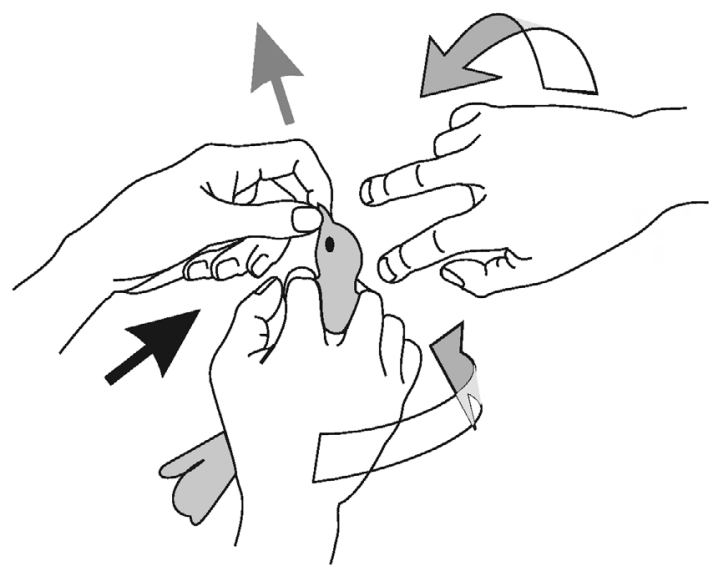

Figure 7.1: How to pass the bird quickly and safely.

\subsubsection{Three-Person Procedure}

The number of birds that can be processed by a two-person team is limited, so if many birds are caught, a three-person team is even more efficient. One person is the ringer, the second is the measurer and the third is the writer. The course of the procedure is still the same, but two working persons process two birds simultaneously; the ringer removes the bird from the storing device (bag or box), rings it and performs 
sexing and ageing. The next person does all measurements. Both working persons: the ringer and the measurer, dictate data one at a time, not simultaneously. This is the point at which it is crucial to be well synchronized! The writer must record the data, correctly filling two rows in the field-sheet. The best possible synchronization is reached by dictating the next bird during the weighing process, which is the slowest element in the procedure. The writer's role is difficult but still possible to perform when he is well trained. It is important to have silence in the laboratory (if silence is a possible state when a hundred tits are waiting for ringing!). In reality, silence means "no one talks". A well-trained team is able to process the bird, on average, within 20-25 seconds, taking all standard measurements using recommended methods and strictly following recommended routines.

\subsection{Extended Routines}

Contrary to normal procedures, where a high level of standardization must be maintained, there are possible arrangements for different extended routines. They depend on the set of data collected and preferences given to the studies being performed. There is more freedom to negotiate these choices when the number of birds is limited and there is enough time to work more slowly. Most problems arise when the number of birds rises and there is competition for time between different studies being performed. This will be discussed in the Alarm Routine section. In all cases, however, the routine applied should be defined in relation to the standard working routine.

When there is little additional data collected, additions may easily be incorporated into the normal routine. Additional measurements/scores may be taken after sex/ age discrimination, or fat scoring if applicable, and wing-formula measurements. In the field-form, there are optional fields located for additional data. Another reason for making additional measurements all together is that they are usually done with special tools, not a standard ruler. Sometimes, they can be done towards the end of a standard procedure. This is usually the case when they are treated as data of secondary importance, so they may be abandoned with little grief.

When non-standard data collection is more time-consuming, and the study is important, it is advisable to do additional data collection after the standard procedure has been performed on all birds caught. Alternatively, a separate person or team can collect the data. This rule should be applied particularly to moult studies, examination for parasites, blood-sampling, etc. Orientation tests can be done parallel to the ringing, since one specified person usually works with tested birds. He may start after the first individual of the species studied has undergone the normal procedure. Individuals selected for special treatment should be put into unique bags and then be hung separately from other birds. 


\subsection{Alarm Routine}

Occasionally, large numbers of birds can be caught at a station, e.g. at the Operation Baltic station, Mierzeja Wiślana, on the best day 3300 birds were caught (more than one thousand are regular there and elsewhere) while more than 800 could be caught in a single net check. This possibility must be taken into consideration before it occurs. For a stressful situation like this, it is important that the chief ringer, as well as all helpers, are psychologically prepared. Since migration peaks are always sudden, people that are not prepared for a sudden rush of birds frequently lose their sensibility and may do totally irrational things.

First of all, constant maintenance of the rules of normal procedure (described in earlier chapters) is recommended. All elements stressed there synergize with successful solutions of problems caused by an extreme bird rush. Here, the most important advice is summarised:

1. The net round should be as simple as possible and cleared so that workers are able to run along it without colliding with twigs and strings nor stumbling on laying branches, stones, etc.; passages under the nets and strings should be avoided.

2. The nets should be made of a kind of material that allows quick removal of birds. Any nets with very thin thread should be taken out of use when mass trapping is expected; specially designed nets which must be closed or slipped along poles when the birds are removed should not be used at all (or opened only when one is sure that there is no rush of birds). If the rush comes suddenly, such nets should be immediately closed.

The nets must be clean of leaves, twigs, etc., and not caught on trees and bushes.

3. The equipment should always be ready for use. The number of necessary dry bags, boxes or baskets should be adequate; it is a good custom to have a special reserve of fresh (never used before) bags ready for a special situation like a rush of birds, particularly in wet weather. Sometimes, if many birds are caught on evening controls, then, a good source of light should be available.

4. There should always be enough rings of all sizes: opened and ready to use, particularly of the ring sizes most commonly used; it is better to have a surplus of a thousand rings than a hundred too few. Having to open rings when the stock is exhausted can be time consuming and problematic.

5. The staff must be trained in the correct removal of birds from nets, in selection by species, and in hanging bird bags in proper places in the laboratory. Furthermore, they should be trained in how to pass birds from hand to hand and how to register data in the field-forms on days with a limited supply of birds. Individual aversions to drill and dull, standardized work should be overcome, people must be carefully trained and motivated to useful routines so that they can "save the birds from death" when a rush occurs. NOTE: the "real" rush (with several hundred birds at 
one single control) is hardly imaginable to people who started their practice at a station where twenty birds are caught per day!

6. At the outset of the control walk, particularly the first one in the morning, always bring many more bags than are probably needed. On a peak day, the actual need may be ten times (or more than that) higher than on a normal day. Lack of bags may seriously disturb the rhythm of controls and has been the cause of birds' death, when too many birds are put together because the helper doesn't want to return for more bags, in more than one case. Therefore, it is a good custom to assess the number of birds in the first nets and estimate whether there could be a coming rush already at the outset of the control walk. If there seems to be a need for more bags, return quickly to the station and warn the chief-ringer about such a prospect; sometimes, the expectation may turn out to be unfounded, in other cases it will save birds' lives and the ringer from the stress resulting from the collapse of routines (and a load of responsibility for the birds). Also, keep in mind that the staff will be grateful for smooth work and smooth routines; at the beginning of a day, when the ringer gets notice of an approaching rush, he should immediately wake up all personnel and order who will be a writer and who will go where.

7. Remove the birds by species from the nets when there are many birds of two or more species. The bag should not be closed after each bird; see How to free $a$ bird... - p. 45. Strictly follow the rules, restricting the number of birds in a bag and their transportation. The decision of whether to put the birds into boxes or baskets is made by the chief-ringer. Do not mix birds from two controls; it must be absolutely clear which birds were collected simultaneously.

8. In most cases, the net control is done by one person or by two attending training together, or simply for social reasons. When a rush occurs there are two possibilities when two persons work on the same control path:

(1) Many birds are known to be waiting for removal and the staff is numerous enough to allow two persons to work together on one control path. They walk together following the normal course of the control (a fixed direction of walk); remove different species when working together at one net or work on two sides of the net when birds have been caught from both sides,

(2) One single person goes for the control walk and does not return within the expected time. In such cases, the second person sent by the chief-ringer must go in the opposite direction, and when he runs across the first one the two together should return to the laboratory without removing new birds from the nets that are passed for the second time.

9. Keep a time schedule of the control walks! Keeping the time schedule during a peak of catching means being no more than fifteen minutes late. Remember that birds staying in the nets for a longer time get more entangled and their removal takes longer. 
10. Work with the three-person or at least the two-person procedure at the laboratory; one-man-work is highly inefficient. There may be a gain of momentum if the ringer assists in removing birds at the first control walk and then returns with a helper to work in the laboratory as a two-person team. Since there are enough birds for continuous work, and handling speed is a key factor on peak days, the ringer must then stick to the laboratory with one or two helpers, according to the procedure, because if the whole staff concentrates exclusively on removing birds, not before long bags and other storing devices will be full of birds waiting for treatment. People working in the laboratory should be asked for silence. The working team should receive only necessary directions and information. Any additional voices disturb the rhythm of dictation and can lead to repetition of measurements and errors in writing.

There is no single formula for winning the battle with hordes of birds in such a way that all requirements of this strategic game will be fulfilled. The birds fly to their migration goal ringed and measured, while you and your staff will be still alive and satisfied because of the high quality of the work done.

Finally: all people must be psychologically prepared to make a maximum effort at any position: as ringer, writer or helper. The most important thing when a rush occurs is that the chief-ringer does not panic; this usually leads to unwise decisions, resulting in avoidable deaths of birds or at least in unnecessary losses of data, since data from peak days could be of great scientific value.

There are a few general observations, which could be helpful when it comes to evaluating a "rush" situation:

(1) In practice, a really huge rush of birds seldom lasts more than three to five hours, so for a moment you may be close to making desperate decisions. This stage is usually reached during the third hour of the rush. You are also close to a report from the helpers ,we have ten birds from the last control walk”. The timing of peaks differs a little and is both species and site dependent, e.g. at Mierzeja Wiślana, Poland: thrushes: only at first control walk, the Robin: the first two walks, tits: mostly the three to four first hours (sometimes later in the day, but for a shorter time), the Goldcrest: three to four hours, but starting from the second control walk etc. But on a grey and misty October day, goldcrests may also move about till dusk; this means 12 hours of uninterrupted ringing by exhausted staff! The possibility of reversed migration in the afternoon should always be kept in the corner of the chief ringer's eye. An outbreak of starving siskins will last from dawn till dusk, and spring arrivals of chaffinches, robins and goldcrests on islands in the Baltic and Kattegat may last well into the afternoon; a number of ringing catastrophes are known to have occurred under such conditions. It is recommended to have a look at earlier catching files of the station in order to learn the patterns of different species. 
(2) Dead birds are inevitably connected with the numbers caught during catch. When more birds are caught, the theory of probability tells us that there will be more dead birds. In addition, the probability for unavoidable deaths, due to predation, strangulation, and exhaustion, is higher on peak days than on quiet days. When few individuals are caught; the total catching mortality is a weighed as the sum of these probabilities and it never equals zero. On a peak day, accidental losses, like a couple of dead birds in a bag, caused by e.g. instinctive stronger hold of a bag full of birds falling down from the bag hanger, are much more probable. Such singular losses, however, are a far ways away from a real ringing catastrophe.

The chief-ringer is the only decision-maker at the station unless there is another wellqualified ringer to whom the chief-ringer could pass responsibility to decide on duties of the staff members. The decision-maker must be well informed about what is going on in the field: how many birds there are from the current control and if the birds are very active, for instance. Apart from decisions concerning the organization of work, the chief-ringer must make some other key decisions alone, and these depend on his appraisal of the staff's abilities to cope with the expected number of birds, taking into consideration the expected time distribution of other potentially occurring species (see above). A few standard emergency decisions will be given here in order of importance:

1. close special nets that are time-consuming when active. If these nets are not designed for a special study, the decision should be automatic when a rush of birds is observed,

2. stop any additional data collection. This should be done as soon as it is obvious that the day is a peak day, unless the data have a very high priority within the station programme. In such a case the following decision (3) could come first,

3. Stop taking standard measurements. It is very important and must be emphasized: stop all standard measurements at once, not in a few steps; only ringing and sexing/ageing should be continued; this is a key decision for the data collection and it should be undertaken in a situation when there is real danger to the birds (but not because we are hungry and tired!): (1) the birds become weak because of poor physiological condition, low fat reserves caused by a long flight and/or bad weather. Some exhausted birds are always observed during intensive migration, and they are selected both by catching stress and natural migration risk. A really dangerous situation occurs when ringed and released birds do not fly away but stay around the ringer, most of them after a short rest go farther, but some die. The key species is always the species in the worst condition; (2) The ringer estimates that he is not able to ring all waiting birds within a reasonable time, even if the birds seem to be in sufficiently good condition (Table 7.1); (3) The birds are wet and it is dangerous to have them stored in bags, and (4) There is lack of bags and storing devices which may cause disturbance in the rhythm of control walks. 
4. When the weather is favourable, and there is a group of nets with much lower catching ability at the end of the control path, it is possible to have them checked only every two hours. This is an exception and the decision should be based on a good knowledge of local catching distribution. The rush in itself may mean new conditions of these nets!

5. The most difficult decision is to close the nets; this always means an interruption of the seasonal dynamics of the station and a vacant space in its monitoring data; in addition, the proper closing of nets takes time that could be spent on removing birds from other nets. These birds will have to wait longer and hence become more entangled.

Every emergency decision should be cancelled as soon as the chief-ringer estimates that the situation is no longer dangerous: the number of birds waiting is low enough, the individuals are in good condition and the rush is over. It must be remembered that when the standard set of measurements is started anew, the set should be complete.

When the rush is over, not earlier, the staff may quietly have its lunch (for breakfast it is too late), clean the laboratory (there is usually a mess of lost feathers, excrement, dirty bags and boxes) and start to prepare rings for the next day (if you need to do so), peak days often come in a sequence, e.g. once, at Mierzeja Wiślana, Poland during 21 days there was an average of 1000 catches daily. During such circumstances it may be worthwhile to wake up people earlier than normal and let them have breakfast prior to the first control walk.

Table 7.1: Time limits for storing caught birds.

\begin{tabular}{llll}
\hline Most common fat score & $T 0$ & $T 1$ & $T 2+$ \\
\hline Time limit* & $2 \mathrm{~h}$ & $3 \mathrm{~h}$ & $4 \mathrm{~h}$ \\
\hline
\end{tabular}

*Counting from the nominal hour of the control of nets (e.g. birds from the control at 6.00 and scored as $T 1$ should be free till 9.00) 